\title{
Estrogen Regulates MAPK-Related Genes through Genomic and Nongenomic Interactions between IGF-I Receptor Tyrosine Kinase and Estrogen Receptor-Alpha Signaling Pathways in Human Uterine Leiomyoma Cells
}

\author{
Linda Yu, ${ }^{1}$ Alicia B. Moore, ${ }^{1}$ Lysandra Castro, ${ }^{1}$ Xiaohua Gao, ${ }^{1}$ Hoang-Long C. Huynh, ${ }^{1}$ \\ Michelle Klippel, ${ }^{1}$ Norris D. Flagler, ${ }^{2}$ Yi Lu, $^{3}$ Grace E. Kissling, ${ }^{3}$ and Darlene Dixon ${ }^{1}$ \\ ${ }^{1}$ Molecular Pathogenesis Group, National Toxicology Program (NTP) Laboratory, NTP, Department of Health and Human Services \\ (DHHS), National Institute of Environmental Health Sciences (NIEHS), National Institutes of Health (NIH), Research Triangle Park, \\ NC 27709, USA \\ ${ }^{2}$ Cellular and Molecular Pathology Branch, NTP, Department of Health and Human Services (DHHS), National Institute of \\ Environmental Health Sciences (NIEHS), National Institutes of Health (NIH), Research Triangle Park, NC 27709, USA \\ ${ }^{3}$ Biostatistics Branch, Department of Health and Human Services (DHHS), National Institute of Environmental Health Sciences \\ (NIEHS), National Institutes of Health (NIH), Research Triangle Park, NC 27709, USA
}

Correspondence should be addressed to Darlene Dixon, dixon@niehs.nih.gov

Received 2 March 2012; Accepted 22 July 2012

Academic Editor: Bertrand Jean-Claude

Copyright (C) 2012 Linda Yu et al. This is an open access article distributed under the Creative Commons Attribution License, which permits unrestricted use, distribution, and reproduction in any medium, provided the original work is properly cited.

\begin{abstract}
Estrogen and growth factors play a major role in uterine leiomyoma (UtLM) growth possibly through interactions of receptor tyrosine kinases (RTKs) and estrogen receptor-alpha (ER $\alpha)$ signaling. We determined the genomic and nongenomic effects of $17 \beta-$ estradiol $\left(\mathrm{E}_{2}\right)$ on IGF-IR/MAPKp44/42 signaling and gene expression in human UtLM cells with intact or silenced IGF-IR. Analysis by $\mathrm{RT}^{2}$ Profiler PCR-array showed genes involved in IGF-IR/MAPK signaling were upregulated in UtLM cells by $\mathrm{E}_{2}$ including cyclin D kinases, MAPKs, and MAPK kinases; RTK signaling mediator, GRB2; transcriptional factors ELK1 and E2F1; CCNB2 involved in cell cycle progression, proliferation, and survival; and COL1A1 associated with collagen synthesis. Silencing (si)IGF-IR attenuated the above effects and resulted in upregulation of different genes, such as transcriptional factor ETS2; the tyrosine kinase receptor, EGFR; and DLK1 involved in fibrosis. $\mathrm{E}_{2}$ rapidly activated IGF-IR/MAPKp44/42 signaling nongenomically and induced phosphorylation of $\mathrm{ER} \alpha$ at ser118 in cells with a functional IGF-IR versus those without. $\mathrm{E}_{2}$ also upregulated IGF-I gene and protein expression through a prolonged genomic event. These results suggest a pivotal role of IGF-IR and possibly other RTKs in mediating genomic and nongenomic hormone receptor interactions and signaling in fibroids and provide novel genes and targets for future intervention and prevention strategies.
\end{abstract}

\section{Introduction}

Although the exact etiology of uterine leiomyomas (fibroids) is unknown, the fact that they develop during the reproductive years and regress after menopause indicates that they are hormonally regulated [1-3]. The important role of estrogen in the promotion of uterine leiomyoma growth has been well supported through clinical and biological studies [4-6]. However, the overexpression of growth factors and their receptors, such as the type I insulin-like growth factor (IGFI) and IGF-I receptor (IGF-IR), shows that sex steroids are not the only modulators of leiomyoma cell proliferation and exuberant extracellular matrix formation observed in many fibroids [2, 7-9]. Studies have revealed that IGF-I expression is most abundant in leiomyomas during the proliferative phase of the menstrual cycle $[10,11]$. The expression of IGF-I mRNA increases in leiomyomas, and estrogen receptor alpha $(\mathrm{ER} \alpha)$ mRNA is positively correlated with IGF-I mRNA levels, which implies as we and others have shown that estrogen upregulates the gene encoding IGF-I through ER $\alpha$ in leiomyoma tissue and cells [10-13]. 
The accumulated data from extensive studies of breast cancer, another disease that is often hormonally regulated, have shown that the interactions of estrogen/ER $\alpha$ with IGFIR/MAPK signaling can occur at different molecular levels $[14,15]$. It is known that $17 \beta$-estradiol $\left(E_{2}\right)$ primarily acts through cognate nuclear ER $\alpha$ leading to regulation of gene expression, which has traditionally been defined as genomic estrogen activity. It has also been reported that many of the $\mathrm{E}_{2}$-responsive genes are key signaling molecules that participate in IGF-IR signaling [16]. Alternatively, a cell membrane-associated form of $\mathrm{ER} \alpha$ has been reported to couple with and activate IGF-IR through phosphorylated Shc $[17,18]$, thereby triggering rapid nongenomic effects through transactivation of the IGF-IR. More recently, our and other studies have shown that $\mathrm{E}_{2}$ and environmental phytoestrogens (genistein) can induce $\mathrm{E}_{2}$-dependent signals prompting major biological responses such as gene expression and human uterine leiomyoma (UtLM) cell proliferation $[12,13,19]$. In addition, $\mathrm{E}_{2}$ is able to upregulate IGF-I gene expression $[12,16,20]$ and increases IGF-I synthesis, which leads to activation of IGF-IR $\beta$ and MAPKp44/42 $[19,21]$. Increased activated MAPKp44/42 with enhanced phosphorylation of ER $\alpha$-phospho-ser118 has been observed in uterine leiomyomas, but not in uterine smooth muscle tissue [22].

All of these studies suggest that the effect of growth promoter IGF-I and its receptor IGF-IR and downstream target MAPK-related genes may be regulated by estrogen at genomic and nongenomic levels, and the interaction of $\mathrm{ER} \alpha$ and IGF-IR/MAPKp44/42 may play a pivotal role in fibroid tumorigenesis, but the exact mechanism(s) of how this all occurs is unknown. There are several questions that need to be addressed such as (1) how does estrogen regulate MAPK related gene expression through IGF-I and the IGFIR/MAPKp44/42 pathway; (2) what is the role of $E_{2}$ in the activation of IGF-IR leading to MAPKp44/42 phosphorylation of ER $\alpha$ at the serine 118 site; (3) which specific mediators of the signaling pathways are involved in the interactions of IGF-I/IGF-IR and ER $\alpha$ in uterine leiomyomas. In this study, we explored the regulatory effects of $\mathrm{E}_{2}$ on intermediates of the IGF-IR/MAPK signaling cascade and related gene expression in UtLM cells and identified new genomic mediators involved in fibroid growth and development by genomic array profiling. We also determined if the effects of $E_{2}$ were through genomic and nongenomic interactions of IGF-I, IGF-IR, ER $\alpha$ ser118, and MAPKp44/42 by silencing IGF-IR followed by western blotting, immunoprecipitation, and immunofluorescence microscopy. To our knowledge, this is the first study in human leiomyoma research focusing on determining the profile of $\mathrm{E}_{2}$-mediated IGF-IR/MAPKrelated genes and exploring the genomic and nongenomic interactions of ER $\alpha /$ IGF-IR/MAPKp44/42 pathways.

\section{Material and Methods}

2.1. Cell and Cell Culture. UtLM cells (GM10964) were purchased from Coriell Institute for Medical Research (Camden, NJ, USA) and maintained in MEM (Gibco Life Technologies, Grand Island, NY, USA) with supplements at $37^{\circ} \mathrm{C}$, with $95 \%$ humidity, and 5\% carbon dioxide as previously described [9].

2.2. siIGF-IR and Real-Time Profiler PCR Array. The RT ${ }^{2}$ Profiler PCR Array System (MAP Kinase Signaling Pathway PCR Array, PAHS-061) from SABiosciences (Frederick, MD, USA) was used to analyze gene expression related to the MAPK signaling pathway in UtLM cells in response to $\mathrm{E}_{2}$ (Sigma, St. Louis, MO, USA) treatment, with and without IGF-IR silencing (siIGF-IR). The transfection of siIGF-IR oligo targeting human IGF-IR gene $\left(5^{\prime}\right.$ to $3^{\prime}$ CGUCUUCCAUAGAAAGAGAtt) and a control scrambled siRNA ( $\mathrm{siScr}$ ) with a nonsense sequence designed to have no significant sequence similarity to mouse, rat, or human transcript sequences (Ambion, Foster City, CA, USA) into cells was done using Lipofectamine (Invitrogen, Carlsbad, CA, USA) as a transfection agent following the manufacturer's protocol. UtLM cells were incubated in serum-free medium containing $0.001 \%$ of vehicle (ethanol) for $24 \mathrm{~h}$ after siIGF-IR, then treated with $\mathrm{E}_{2}\left(10^{-8} \mathrm{M}\right)$, and harvested at $24 \mathrm{~h}$ using Trizol Reagent (Invitrogen). Total cellular RNA was extracted from the cells using Qiagen RNeasy Mini Kit (SABiosciences) followed by the RT ${ }^{2}$ First Strand C-03 Kit (SABiosciences) to remove any residual contamination from the RNA samples with $2 \mu \mathrm{g}$ purified RNA per treatment condition. The template combined with the $\mathrm{RT}^{2}$ SYBR green/ROX qPCR mix ( $25 \mu \mathrm{L} /$ well) was loaded into a 96-well array plate coated with 84 predispensed MAPK-related genespecific primer sets (SABiosciences) with each treatment condition per plate and processed on a TaqMan ABI Prism 7900 Sequence Detector System (Applied Biosystems, Foster City, CA, USA) according to the $\mathrm{RT}^{2}$ Profiler PCR Array (SABiosciences) manufacturer's protocol. The data analysis was based on the $\Delta \Delta C_{t}$ method with normalization to GAPDH and HPRT (SABiosciences), (http://www.sabiosciences.com/pcrarraydataanalysis.php).

2.3. Real-Time PCR. Real-time (RT) PCR was performed to detect estrogen responsive gene, IGF-I mRNA expression levels following $\mathrm{E}_{2}$ treatment at $0 \mathrm{~min}, 10 \mathrm{~min}, 60 \mathrm{~min}, 24 \mathrm{~h}$, and $48 \mathrm{~h}$ in UtLM cells. Starvation of cells with serum-free medium was the same as described for $\mathrm{RT}^{2}$ Profiler PCR Array and occurred $24 \mathrm{~h}$ prior to $\mathrm{E}_{2}\left(10^{-8} \mathrm{M}\right)$ treatment. Cells were harvested with Trizol Reagent, and total cellular RNA was extracted from the cells using a Trizol Plus RNA Purification Kit (Qiagen, Valencia, CA, USA). One microgram total RNA was used to prepare cDNA and reversetranscribed with Superscript II (Invitrogen). RT-PCR was performed using IGF-I and GAPDH primers [19] with Applied Biosystems Power SYBR Green PCR Mix on an AB cycler. The results were expressed as fold changes compared to untreated groups and normalized with GAPDH.

\subsection{Immunofluorescence Staining (Confocal Microscopy).} Immunofluorescence staining was performed to detect IGFI peptide expression at $0 \mathrm{~min}, 10 \mathrm{~min}, 60 \mathrm{~min}, 24 \mathrm{~h}$, and $48 \mathrm{~h}$, and phospho-ER $\alpha$ ser 118 and phospho-MAPKp44/42 colocalization at $0 \mathrm{~min}, 10 \mathrm{~min}$, and $60 \mathrm{~min}$ in UtLM cells following $\mathrm{E}_{2}$ treatment. The cells were starved the same 
as described for the real-time $\mathrm{RT}^{2}$ Profiler PCR Array for $24 \mathrm{~h}$ prior to $\mathrm{E}_{2}$ treatment at $10^{-8} \mathrm{M}$. The cells were fixed with $4 \%$ paraformaldehyde (Electron Microscopy Sciences, Hatfield, PA, USA), permeabilized with $0.2 \%$ Triton X-100 (Sigma), and blocked with 5\% BSA (Sigma) and $0.1 \%$ gelatin (Sigma) in PBS. The cells were incubated overnight with primary IGF-I goat polyclonal antibody (sc-1422, 1:200 dilution; Santa Cruz Biotechnology, Santa Cruz, CA, USA), phospho-ER $\alpha$ ser118 mouse monoclonal antibody (number 2511, 1:50 dilution; Cell Signaling, Danvers, MA) and phosho-MAPKp44/42 rabbit monoclonal antibody (number 9101, 1:100 dilution, Cell Signaling). Alexa Fluor (Invitrogen) 488 goat anti-rabbit for phospho-MAPKp44/42, Alexa Fluor (Invitrogen) 594 donkey anti-mouse for phosphoER $\alpha$ ser118, and 594 donkey anti-goat for IGF-I $(1: 3000$ dilution) were used as secondary antibodies and DAPI (Invitrogen) for nuclear staining. Normal rabbit, normal mouse, or normal goat serum (Jackson Immunoresearch, West Grove, PA, USA) served as negative controls. Confocal images were taken on a Zeiss LSM510-UV meta (Carl Zeiss Inc, Oberkochen, Germany) using a C-Apochromat 40x/1.2 $\infty / 0.14-0.19$ Korr UV-VIS-IR objective. The $488 \mathrm{~nm}$ laser line from a Krypton/Argon laser was used for excitation of the Alexa 488. A 505-550 nm bandpass emission filter was used to collect this image with a pinhole setting of 1.09 airy unit. For the second channel, the $543 \mathrm{~nm}$ laser line from a Helium Neon laser was used for excitation of the Alexa 594. A $560 \mathrm{~nm}$ longpass emission filter was used to collect the images with a pinhole setting of 1 airy unit.

2.5. Western Blot Analysis. Western blot analysis was performed using a standard procedure as described previously [9] to assess rapid effects of $E_{2}$ on target protein expression in UtLM cells. The siIGF-IR and siScr transfection procedure were the same as described in siIGF-IR and real-time $\mathrm{RT}^{2}$ Profiler PCR Array. The serum-starved cells were treated with $\mathrm{E}_{2}\left(10^{-8} \mathrm{M}\right)$ at 0,10 , and $60 \mathrm{~min}$. The protein was extracted with a lysis buffer as previously described [9]. Primary antibodies used for the western blotting were as follows: rabbit polyclonal anti-phospho-IGF-1R $\beta$ Tyr1131/IR$\beta$ Tyr1146 (number 3021, Cell Signaling), rabbit polyclonal anti-IGF-IR $\beta$ (sc-713, Santa Cruz Biotechnology), rabbit polyclonal anti-phospho-Shc (number 2434, Cell Signaling), rabbit polyclonal anti-Shc (sc-288, Santa Cruz), rabbit polyclonal anti-ER $\alpha$ (sc-7207, Santa Cruz), mouse monoclonal anti-phospho-ER $\alpha$ Ser118 (number 2511, Cell Signaling), rabbit polyclonal anti-MAPKp44/42, and rabbit polyclonal anti-phospho-MAPKp44/42 (number 9201 and number 9101, Cell Signaling). The rabbit anti-ER $\alpha$, rabbit anti-IGF-IR $\beta$, and rabbit anti-Shc antibodies used in the western blotting studies were used for immunoprecipitation samples. Primary antibodies were detected with horseradish peroxidase-conjugated secondary anti-mouse or anti-rabbit antibodies (GE Healthcare, Buchinghamshire, UK).

2.6. Immunoprecipitation. A Seize Primary Immunoprecipitation Kit (Pierce Biotechnology, Rockford, IL, USA) was used to detect the association of ER $\alpha$, IGF-IR $\beta$, and Shc in the cells treated with $E_{2}$. The kit was used because IgG of
anti-ER $\alpha$, which was used to pull down Shc, and IGF-IR $\beta$, has the same molecular weight as the target protein Shc and this kit allows the immunoglobulin to remain adherent to Aminolink Plus Gel following elution. The procedures were done according to the manufacturer's protocol [9]. Briefly, $200 \mu \mathrm{g}$ of ER $\alpha$ rabbit polyclonal antibody (Santa Cruz) were coupled to $50 \mu \mathrm{L}$ of $50 \%$ of Aminolink Plus Gel Slurry in coupling buffer overnight at $4^{\circ} \mathrm{C}$. The coupled gel and antibody complex was incubated with $300 \mu \mathrm{g}$ of the total protein harvested from the cells treated with $\mathrm{E}_{2}$ at 0,10 , and 60 min same as described in western blotting procedures in binding buffer overnight at $4^{\circ} \mathrm{C}$. The gel was washed three times with washing buffer. Only the antigens (Shc and IGFIR) in the antigen-antibody complexes were eluted by the elution buffer (all buffers were supplied in the kit) and stored for western blot analysis.

2.7. Statistics. The experiments for RT-PCR of IGF-I mRNA expression, immunoprecipitation, and western blot analysis were repeated at least three times independently. The data obtained from RT-PCR were expressed as mean \pm SEM, and the two-tailed Student's $t$-test was used to compare statistical significance between different groups and between various time points. Most data obtained from immunoprecipitation and western blot analyses were not normally distributed, hence, nonparametric statistical methods and Mann-Whitney tests [23] were used to determine statistically significant differences between silenced and nonsilenced IGF-IR groups at various time points after $E_{2}$ treatment in UtLM cells with respect to ratio of band intensity of phosphorylated/total protein (mean \pm SEM) of IGF-IR, Shc, MAPKp44/42, and ER $\alpha$ ser 118 expression. The statistical significance was defined as one-sided $P<0.05$.

For the RT ${ }^{2}$ Profiler PCR Array data, the receptor tyrosine kinase IGF-IR, MAPK signaling pathway, and fibrosisrelated genes were chosen to be analyzed. The fold changes in response to $E_{2}$ treatment were calculated separately for silenced and non-silenced IGF-IR groups $(<-2$ or $>2$ for either groups) and examined with scatter plots.

\section{Results}

3.1. Differential Expression of IGF-IR/MAPK-Related Genes Mediated by $E_{2}$ with and without IGF-IR Gene Knockdown in UtLM Cells. In order to explore signaling intermediates of the IGF-IR/MAPK cascade and related genes regulated by $\mathrm{E}_{2}$ and find new genomic mediators of fibroid growth and development, we performed genomic arrays to determine MAPK-related gene profiles mediated by $\mathrm{E}_{2}$ with and without IGF-IR gene knockdown. We found 35 genes related to the IGF-IR/MAPK signaling pathway and fibrosis that were differentially expressed between the groups with or without $\mathrm{E}_{2}$ treatment at $24 \mathrm{~h}$ with a functional IGF-IR (scrambled siRNA; siScr), compared to those groups under siIGF-IR conditions (Table 1, Figure 1) within a total of 62 differentially expressed MAPK-related genes (see supplementary material available online at doi:10.1155/2012/204236, Table 1). The PCR array showed that $E_{2}$ exposure in UtLM cells with a functional IGF-IR (siScr) resulted in $>2$-fold 


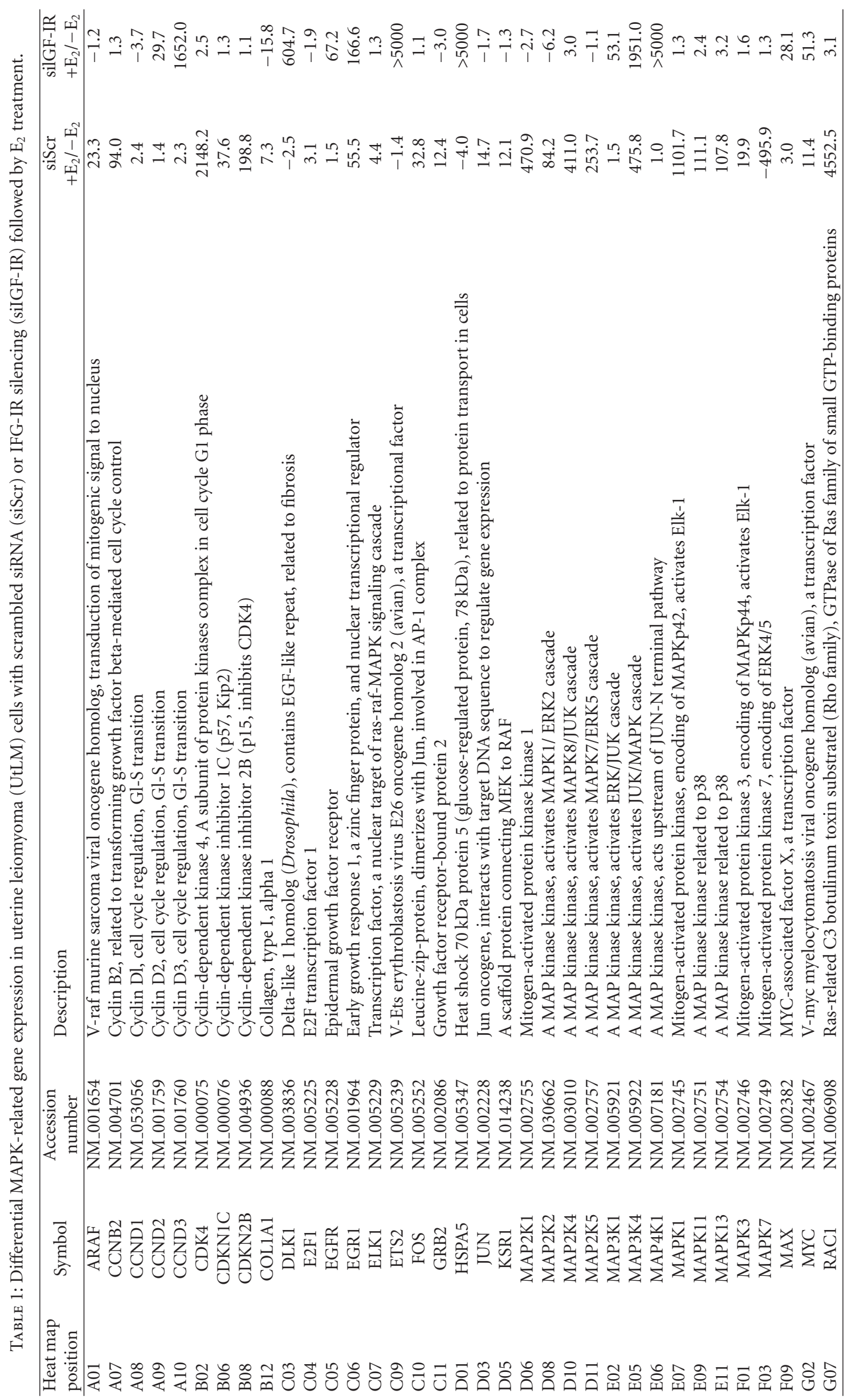


siScr: $+\mathrm{E}_{2} /-\mathrm{E}_{2}$

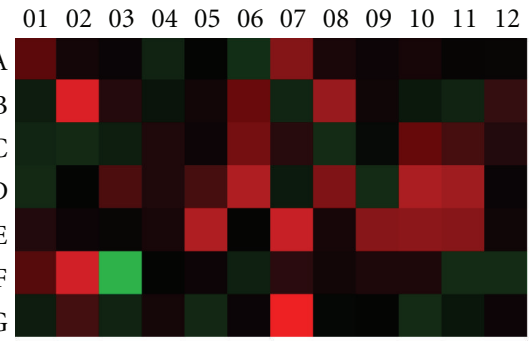

silGF-IR: $+\mathrm{E}_{2} /-\mathrm{E}_{2}$
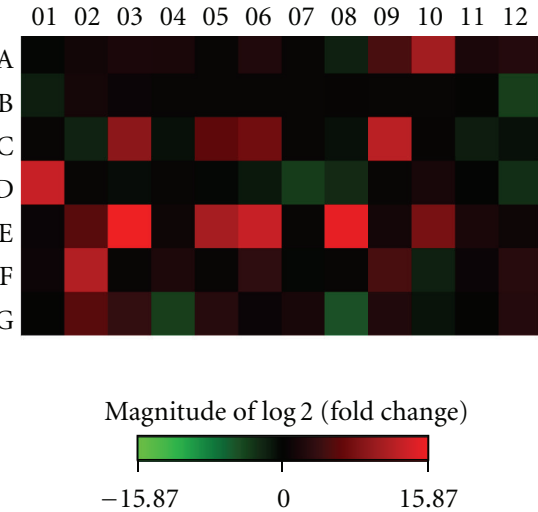

(a)

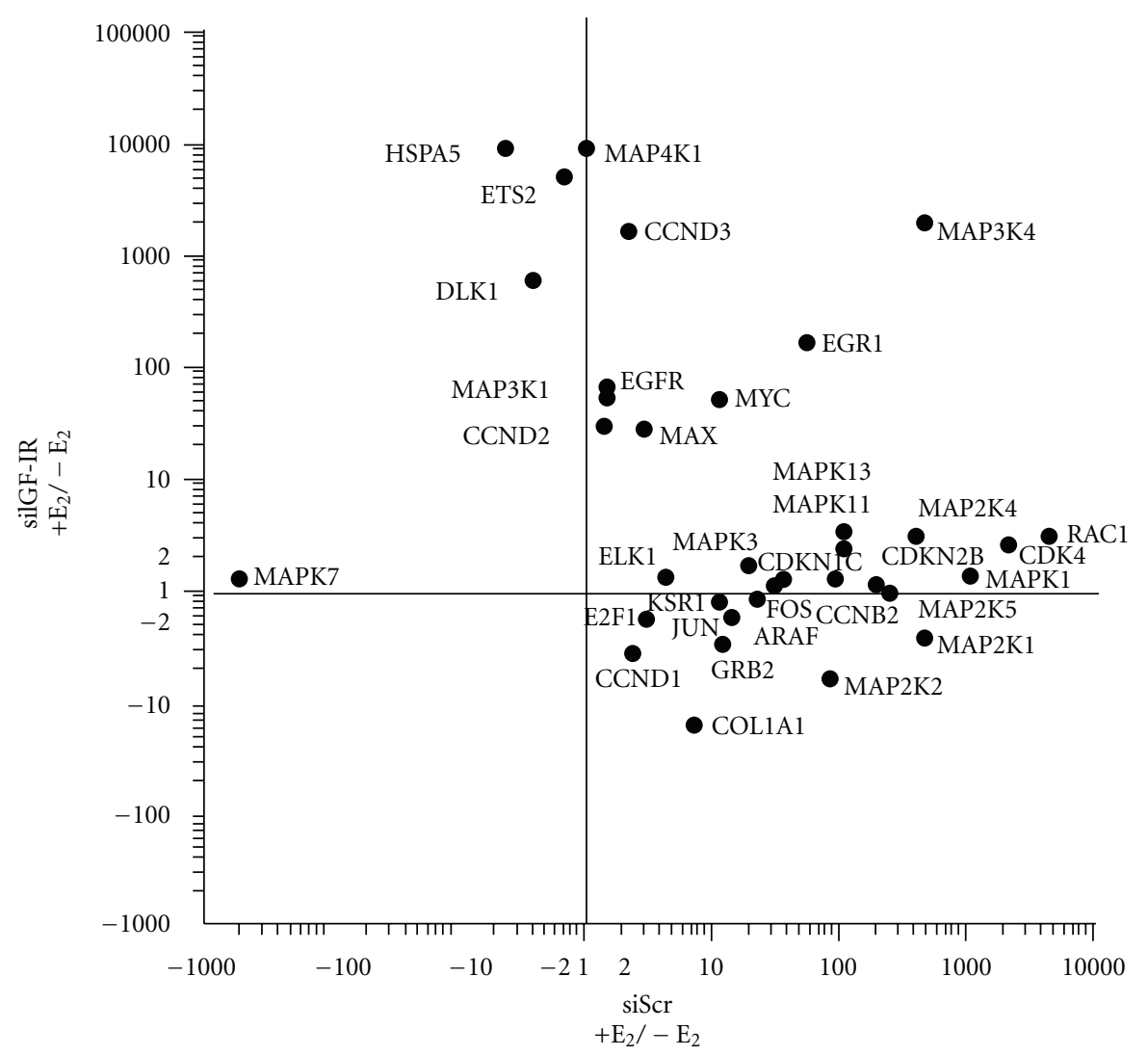

(b)

Figure 1: Differential MAPK pathway-related gene expression in UtLM cells mediated by $17 \beta$-estradiol $\left(\mathrm{E}_{2}\right)$ in the presence of scrambled siRNA (siScr) or IGF-IR silencing (siIGF-IR). (a) Heat maps of real-time RT ${ }^{2}$ Profiler PCR Array of MAPK-related genes. The red areas represent the genes that are upregulated, and the green areas represent the genes that are downregulated by $\mathrm{E}_{2}$ treatment. (b) Plot of fold changes of MAPK-related genes in response to $\mathrm{E}_{2}$ treatment in UtLM cells with siScr or silGF-IR.

upregulation of 27 genes and $<-2$-fold downregulation of 3 genes involved in the IGF-IR/MAPK signaling cascade at $24 \mathrm{~h}$ as shown in a heat map (Figure $1(\mathrm{a})$ ) and by fold changes (Figure 1(b)); the other 5 genes were unchanged ( $<2$-fold and $>-2$-fold). Those genes upregulated $>2$-fold in the presence of an intact IGF-IR included several Dtype cyclins and other cyclin-dependent kinases involved in cell cycle progression, growth factor receptor-bound protein (GRB2), and ARAF associated with IGF-IR signaling through MAPK, MAPKs, and MAPK kinases involved in proliferation, differentiation, and survival. Collagen type I alpha I (COL1A1) which is involved in collagen synthesis and fibrosis, a prominent feature of fibroids, and transcriptional factors ELK1, E2F1, and EGR1 were upregulated as well. 


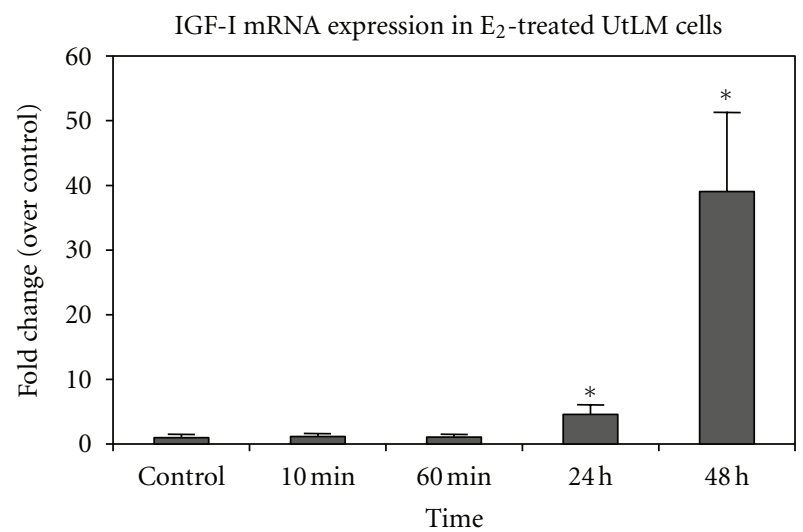

(a)
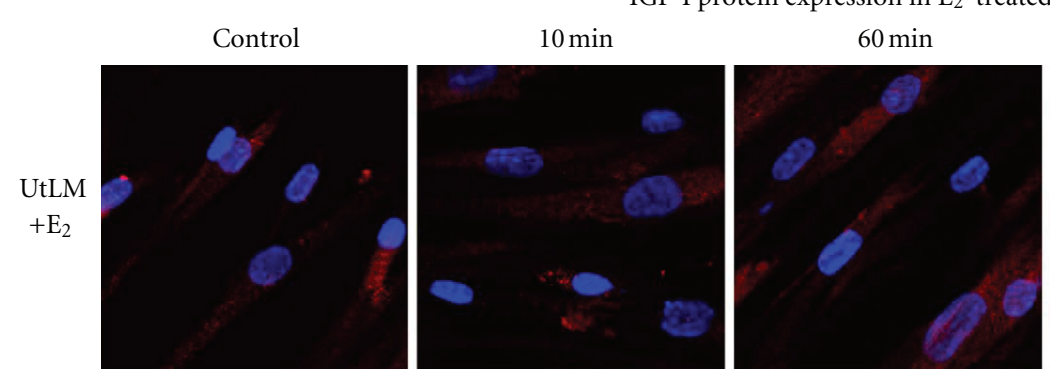

$24 \mathrm{~h}$
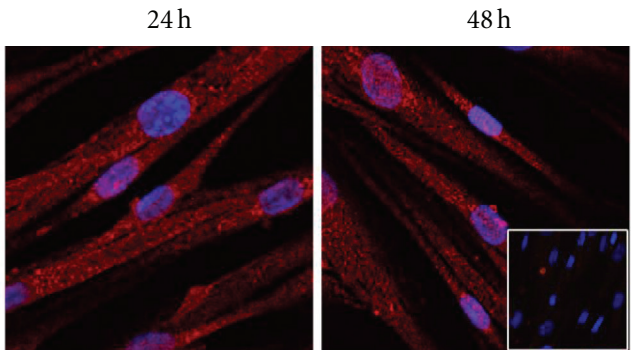

(b)

FIGURE 2: IGF-I mRNA and IGF-I peptide expression levels induced by $17 \beta$-estradiol ( $\mathrm{E}_{2}$ ) in UtLM cells. (a) IGF-I gene expression in UtLM cells following $\mathrm{E}_{2}$ treatment at 0 (control), 10 and $60 \mathrm{~min}$, and $24 \mathrm{~h}$ and $48 \mathrm{~h}$. (b) IGF-I protein expression in UtLM cells following $\mathrm{E}_{2}$ exposure at 0 (control), 10 and $60 \mathrm{~min}$, and $24 \mathrm{~h}$ and $48 \mathrm{~h}$. Inset: Negative control with normal mouse IgG. Representative of mean \pm SEM from three independent experiments. ${ }^{*} P \leq 0.05$ versus control.

Also, RAC1, a Rho GTPase, involved in the regulation of several cellular processes and often activated following stimulation of RTKs [24], such as IGF-IR was increased.

The upregulated genes induced by $\mathrm{E}_{2}$ in the presence of an intact IGF-IR were mostly abrogated, and the 5 unchanged genes observed in the presence of a functional IGF-IR were upregulated after IGF-IR was silenced in UtLM cells. The $\mathrm{E}_{2}$ treatment with siIGF-IR resulted in differential expression of $>2$-fold upregulation of additional genes such as epidermal growth factor receptor (EGFR) involved in cell growth and survival, cyclin D2 (CCND2) and D3 (CCND3) involved in cell cycle progression, v-Ets erythroblastosis virus E26 oncogene homolog 2 (ETS2), a transcriptional factor involved in cell development and tumorigenesis, delta-like 1 homolog (DLK1) involved in fibrosis, and the glucose-regulated protein $78 \mathrm{kDa}$ (HSPA5) associated with monitoring protein transport (Table 1, Figures $1(\mathrm{a})$ and 1(b)). Alternatively, COL1A1 and GRB2, typically increased in the presence of a functional IGF-IR, showed decreased expression with silenced IGF-IR. However, the transcriptional factor EGR1 showed further upregulation when IGFIR was silenced.

The differences in gene expression in response to $E_{2}$ treatment with and without IGF-IR silencing indicate the important role of IGF-IR and its signaling molecules in $\mathrm{E}_{2}$ mediated activation of MAPK and MAPK-related pathways in UtLM cells.

3.2. 17 $\beta$-Estradiol Upregulates IGF-I Gene and Protein Expression in UtLM Cells. To determine if the regulatory effects of $E_{2}$ on MAPK-related gene expression could also occur through the genomic action of $E_{2}$ on the expression of one of its early response genes and a MAPK and IGF-IR activating peptide, IGF-I, we assessed IGF-I mRNA and protein levels in UtLM cells. We performed real-time RT PCR at 0, 10, $60 \mathrm{~min}$, $24 \mathrm{~h}$, and $48 \mathrm{~h}$ after $\mathrm{E}_{2}$ treatment and found that $\mathrm{E}_{2}$ at $10^{-8} \mathrm{M}$ induced a time-dependent increase in IGF-I gene expression. A prolonged response started at $24 \mathrm{~h}$ and reached maximum levels by $48 \mathrm{~h}$ in UtLM cells $(P<0.05$, Figure $2(\mathrm{a}))$.

Confocal microscopy of immunofluorescence staining for IGF-I protein in UtLM cells further revealed that IGF-I peptide expression was increased by $\mathrm{E}_{2}$ and mostly localized in the cytoplasm, but appeared to translocate to the nucleus at $24 \mathrm{~h}$ and $48 \mathrm{~h}$ (Figure 2(b)). Interestingly, to date, IGF-I protein expression has only been reported to occur in the cytoplasm of uterine leiomyoma cells, although there has been one report of its localization in the nucleus of kidney cells [25]. 

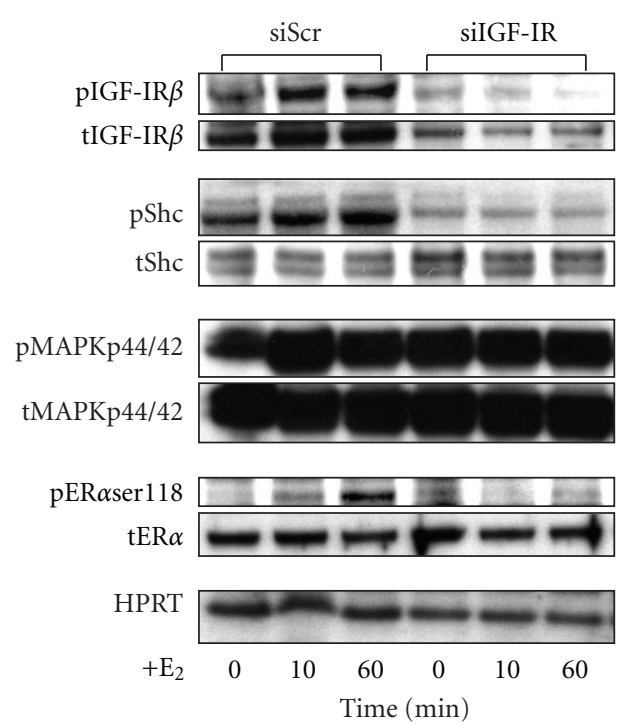

(a)
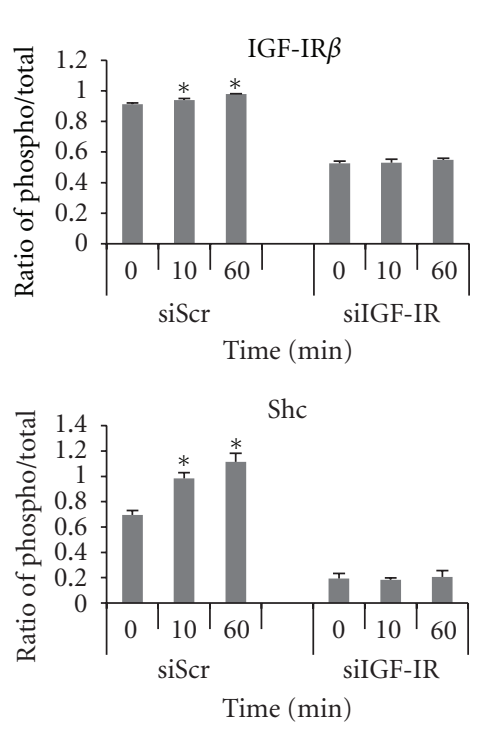
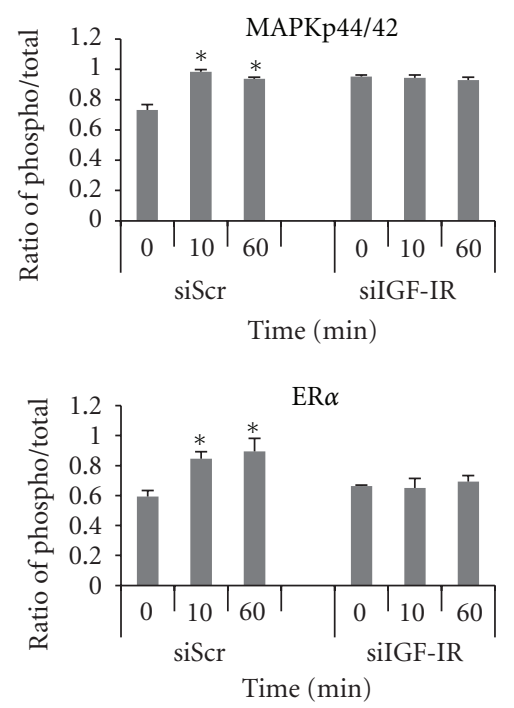

(b)

FIGURE 3: Differential expression of phosphorylated (p)IGF-IR, pMAPKp44/42, and pER $\alpha$ ser118 in UtLM cells with scrambled siRNA (siScr) or IGF-IR silencing (siIGF-IR) followed by $17 \beta$-estradiol $\left(\mathrm{E}_{2}\right)$ treatment. (a) Western blot of IGF-IR/ER $\alpha$ pathway proteins in UtLM cells. (b) Comparison of ratio of densitometric band intensities of phosphorylated (phospho)/total proteins in UtLM cells with siScr or siIGF-IR followed by $\mathrm{E}_{2}$ treatment. Bars represent mean \pm SEM of three independent experiments. $* P<0.05$ versus 0 min.

3.3. Increased Phosphorylation of IGF-IR $\beta$ by $E_{2}$ Leads to MAPKP44/42 Activation and ER $\alpha$ Phosphorylation at serine118 in UtLM Cells. To determine the rapid nongenomic actions of $E_{2}$, we treated UtLM cells with a functional IGFIR with $\mathrm{E}_{2}$ at $10^{-8} \mathrm{M}$ for 0,10 , and $60 \mathrm{~min}$ and measured phosphorylated IGF-IR $\beta$, Shc, and MAPKp44/42 using western blot analysis. We found that there was a quick phosphorylation of IGF-R $\beta$, Shc, and MAPKp44/42 at $10 \mathrm{~min}$ until 60 min in UtLM cells when treated with $\mathrm{E}_{2}$ (Figure 3). It has been previously shown that estrogen treatment can cause an increase in MAPKp44/42 activation and phosphorylation of $\mathrm{ER} \alpha$ at serine118 site in estrogen-responsive breast cancer cell lines [26]. It has also been shown that the IGF-IR downstream protein Shc can act as a transporter for the ER leading to activation of the MAPK signaling cascade [27]. Additionally, in earlier studies, we found that fibroid tissue samples from women in the proliferative phase expressed more phosphorylated ER $\alpha$ ser118 and had more nuclear colocalization and immunoprecipitation of phospho-MAPKp44/42 and ER $\alpha$ ser 118 compared to patientmatched myometrial controls [22]. We therefore examined whether administration of estrogen could produce similar effects in human uterine leiomyoma cells in vitro. As shown in Figures 3(a) and 3(b), the phosphorylation level of ER $\alpha$ at serine 118 rapidly increased at $10 \mathrm{~min}$ and continued until $60 \mathrm{~min}$ in UtLM cells following $\mathrm{E}_{2}$ treatment. These effects were not present with siIGF-IR. Confocal microscopy further revealed that there was increased colocalization of phosphorylated ER $\alpha$ ser 118 and MAPKp44/42 in $\mathrm{E}_{2}$ treated UtLM cells at $10 \mathrm{~min}$ (Figure 4).

3.4. IGF-IR Is Required to Modulate the ER $\alpha$ and MAPK Interaction in UtLM Cells Exposed to $E_{2}$. Immunoprecipitation studies (Figure 5) further revealed that $\mathrm{ER} \alpha$ is associated with both IGF-IR $\beta$ and Shc proteins following $\mathrm{E}_{2}$ treatment, and the amounts of both proteins were decreased when the IGFIR gene was knocked down, which indicates that there is an association between IGF-IR and ER $\alpha$ and between Shc and $\mathrm{ER} \alpha$ in UtLM cells exposed to $\mathrm{E}_{2}$.

\section{Discussion}

The collective view of extranuclear ER $\alpha$ signaling suggests that its transduction pathways and its interaction with IGFIR/MAPK pathways may connect the nongenomic actions of estrogen to genomic responses, since many of them interact and regulate the phosphorylation status and activities of multiple transcription factors, which affect gene expression $[14,27-30]$. Therefore, in this study we first investigated the gene profile involved in the MAPK pathway to explore the effects of $E_{2}$ treatment on IGF-IR/MAPK pathway related gene expression using siIGF-IR and real-time PCR array technology. As shown in Table 1 and Figure 1, UtLM cells treated with $\mathrm{E}_{2}$ in the presence of an intact IGF-IR had a high induction of 27 genes including genes encoding Cyclins, Cyclin Kinases, MAPKs, MAPK kinases, and transcription factors all involved in the cell proliferation, differentiation and survival. However, by silencing the IGF-IR the effects induced by $\mathrm{E}_{2}$ were diminished in UtLM cells and further indicated that $\mathrm{E}_{2}$-mediated MAPK pathway activation requires the presence of the IGF-IR in UtLM cells.

A cascade of MAPKs can be induced by a variety of signaling molecules $[31,32]$. Transduction of the signals is achieved by a sequential series of phosphorylation reactions, wherein each downstream kinase serves as a substrate for the upstream activator. For example, in the mitogenic 


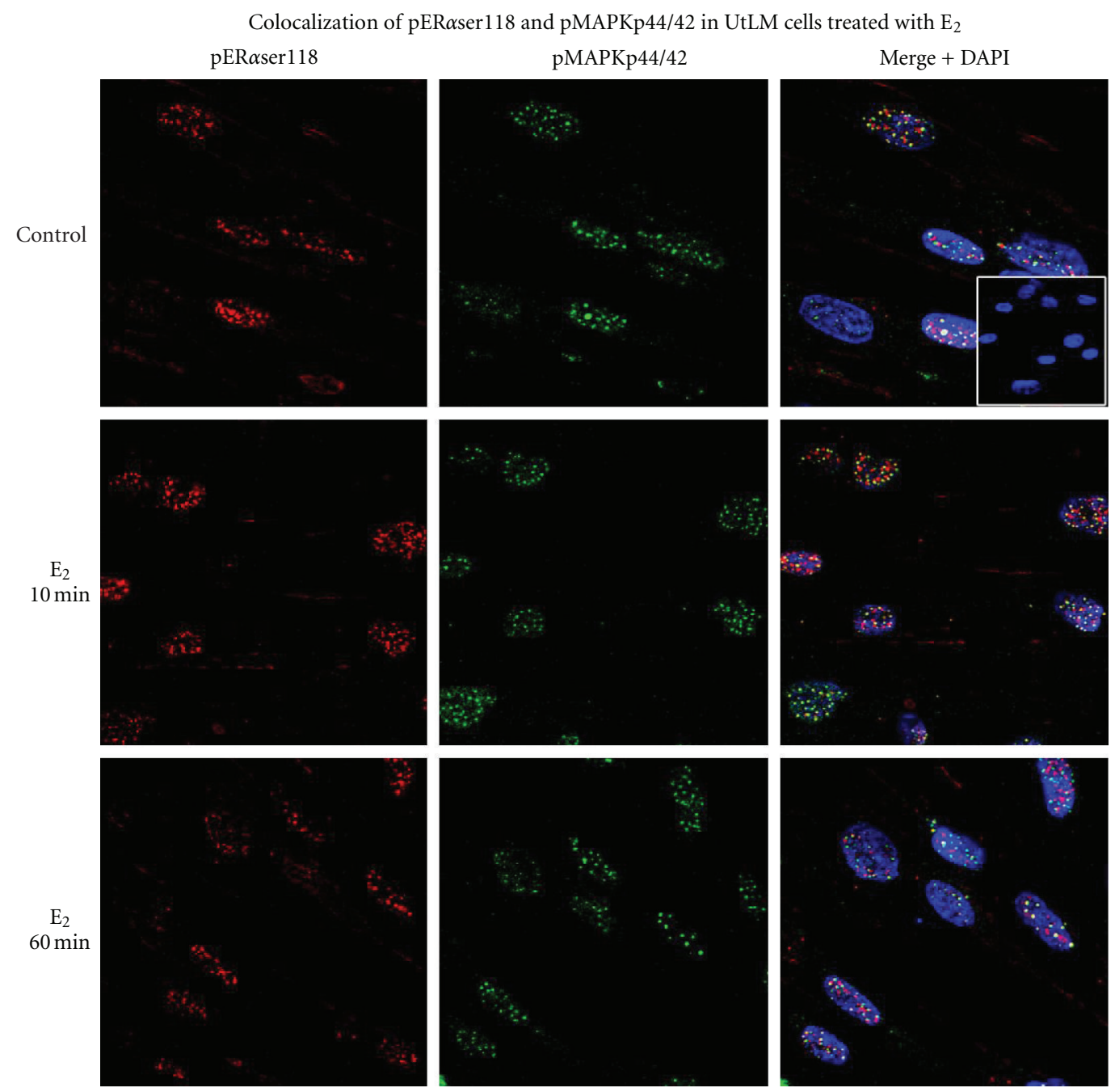

FIGURE 4: Increased colocalization of phosphorylated (p)MAPKp44/42 and pER $\alpha$ ser118 in UtLM cells exposed to $17 \beta$-estradiol ( $\mathrm{E}_{2}$ ). Localization of pER $\alpha$ ser118 expression (red), pMAPKp44/42 (green) and colocalization of both (yellow) in UtLM cells following $\mathrm{E}_{2}$ treatment. The staining was primarily localized to the nucleus. Inset: Negative control with normal mouse and rabbit IgG. Representative of three independent experiments.

extracellular signal regulated kinase (ERK1/2) cascade, the two related mammalian MAPKs, ERK1 and ERK2 (p44mapk and $\mathrm{p} 42 \mathrm{mapk}$ ), are phosphorylated by MAP kinase/ERK kinase (MEK), which is activated primarily by the protein kinase Raf-1 after having been recruited to the plasma membrane by Ras $[33,34]$. In our previous studies, the MAPKp44/42 cascade, preferentially regulating cell growth and differentiation, was upregulated in leiomyomas $[9,22]$. The MAPK-related gene profiling RT-PCR array applied in this study further proves that the expression of genes involved in MAPK pathway, such as MAPK1, MAPK3, and GRB2, and the genes encoding transcriptional factors, ELK1, E2F1, MYC, and MAX are mediated by $\mathrm{E}_{2}$, and their expression levels are elevated when UtLM cells are exposed to $\mathrm{E}_{2}$ in the presence of a functional IGF-IR.

In the highly conserved cyclin family, whose members are characterized by a dramatic periodicity in protein abundance throughout the cell cycle, cyclin D1 can complex with and function as a regulatory subunit of CDK4 or CDK6, which is required for cell cycle G1/S progression [35]. In this study, cyclin D1 and CDK4 expression levels were increased, which further indicates that $\mathrm{E}_{2}$ not only upregulates the MAPK/ERK1/2 pathway, but can also induce cyclin family proteins leading to cell cycle progression from G1 to S phase, thereby increasing cell proliferation. It was interesting to note that some genes encoding cyclin kinase inhibitors, such as $\mathrm{CDKN} 2 \mathrm{~B}$, were also increased following $\mathrm{E}_{2}$ exposure and may have been increased to counterbalance the extremely high expression of CDK4. These findings are consistent with the concept of different cyclins and their kinases exhibiting distinct expression and degradation patterns which contribute to the temporal coordination of each mitotic event [35].

The abrogation of upregulation of genes by $E_{2}$ in the presence of siIGF-IR in UtLM cells further strengthened our hypothesis that IGF-IR plays an important role in the 


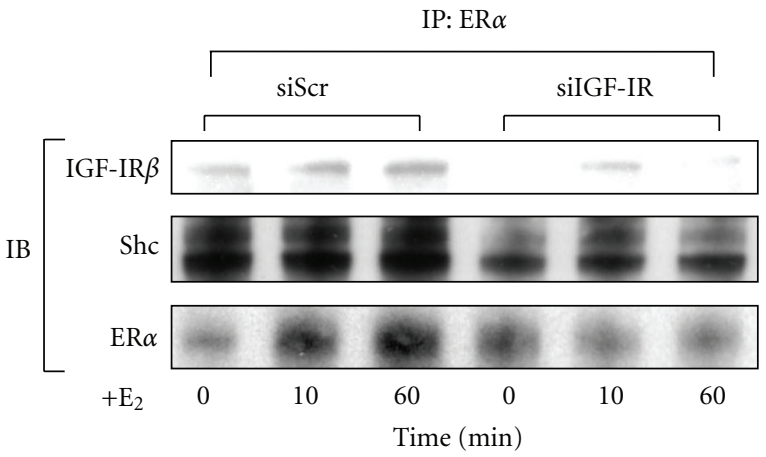

(a)

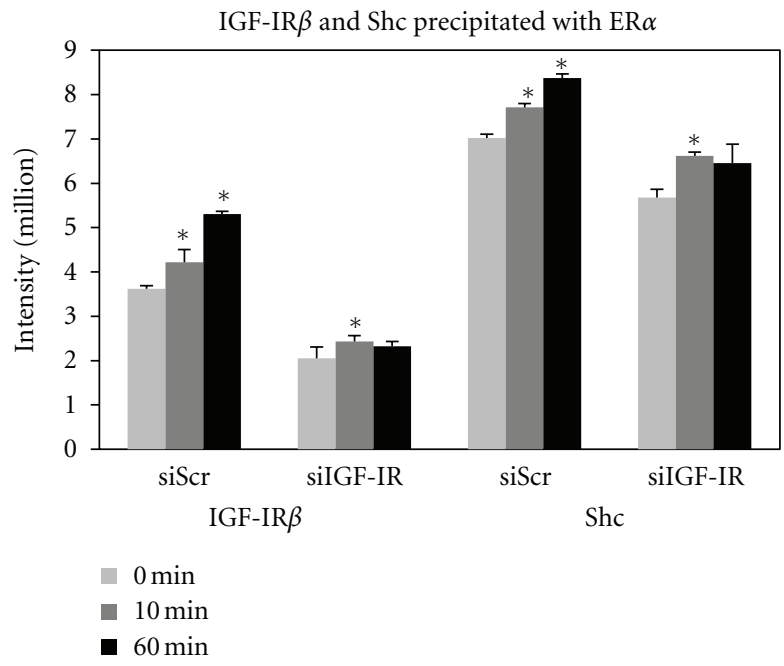

(b)

FIGURE 5: Increased immunoprecipitation of IGF-IR and Shc with ER $\alpha$ in cells exposed to $17 \beta$-estradiol (E $\mathrm{E}_{2}$ ). (a) Interactions between IGF$\operatorname{IR} \beta$ and Shc with ER $\alpha$ in UtLM cells were determined by immunoprecipitation (IP). (b) Comparison of densitometric band intensity of immunoblots (IB) in UtLM cells with siScr or siIGF-IR followed by $\mathrm{E}_{2}$ treatment. Representative of three independent experiments. Bars represent mean intensities \pm SEM. ${ }^{*} P<0.05$ versus 0 min.

crosstalk between the estrogen/ER $\alpha$ and IGF-I/MAPKp44/42 pathways. However, other genes were differentially expressed by $\mathrm{E}_{2}$ treatment in UtLM cells with and without siIGFIR, which indicates that with silencing of the IGF-IR, other mechanisms compensated in response to $\mathrm{E}_{2}$ exposure, resulting in differential gene expression. The increased EGFR, EGR1, CCND2, and CCND3 gene expression pattern with siIGF-IR suggests that $\mathrm{E}_{2}$ treatment promotes alternative pathways for growth and survival when IGF-IR levels are decreased in UtLM cells. In other genes, such as DLK-1, involved in fibrosis [36], the expression level was increased, and COL1A1, a gene involved in collagen synthesis and fibrosis, which is typically increased in the presence of a functional IGF-IR [37, 38], was decreased after siIGF-IR further indicating that IGF-IR may play an important role in fibrosis in uterine leiomyomas.

We next investigated whether $\mathrm{E}_{2}$ upregulates IGF-I and IGF-IR, and their target proteins in leiomyoma cells, and what mechanisms are involved in the interaction between $\mathrm{E}_{2} / \mathrm{ER} \alpha$ and IGF-I/IGF-IR pathways. We found that IGFI gene and protein expression levels increased during the course of $E_{2}$ exposure with a peak fold-change at 48 hours in UtLM cells; this prolonged response indicates a possible mechanism of IGF-I gene expression mediated by $\mathrm{E}_{2}$ at a genomic level. We also found that phosphorylated ER $\alpha$ ser118, IGF-IR $\beta$, and their target protein MAPKp44/42 were all increased within minutes after $\mathrm{E}_{2}$ treatment. The rapid activation of IGF-IR and its target downstream proteins indicates that the interaction between $\mathrm{E}_{2}$ and IGFIR is mediated by nongenotropic signaling, that is, by kinase-initiated events that do not involve estrogen receptor binding to canonical steroid response elements on DNA $[18,28]$. Furthermore, increased colocalization of phosphoMAPKp44/42 and ERaser118 occurred in UtLM cells 10 minutes after $\mathrm{E}_{2}$ treatment. These results are consistent with the findings that several mechanisms are associated with $\mathrm{E}_{2}$ exposure, including rapid activation of IGF-IR and MAP kinase, a nongenomic process observed in estrogenresponsive breast cancer cell lines [39], which could lead to $\mathrm{ER} \alpha$ activation at serine 118 [14, 28].

The molecules involved in the nongenomic signaling process have been identified. More recently, it has been 


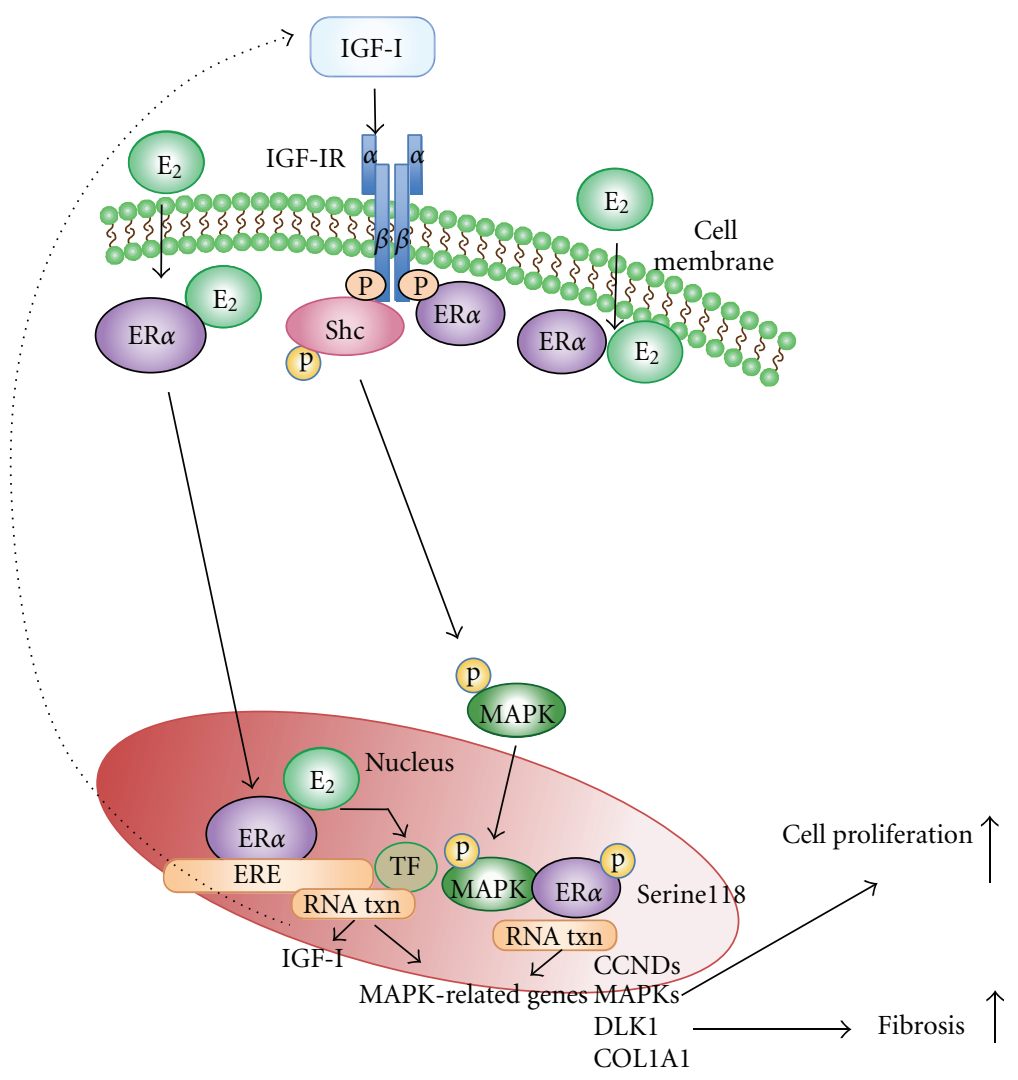

FIGURE 6: Schematic illustration of genomic and nongenomic actions of ER $\alpha$ on target gene transcription. Genomic actions involve the translocation of cytoplasmic $\mathrm{E}_{2}$-ER $\alpha$ complexes to the nucleus which can then bind directly to estrogen response elements (EREs) in target gene promoters or nuclear $\mathrm{E}_{2}$-ER $\alpha$ complexes. These complexes are tethered through protein-protein interactions to a transcription factor complex (TF) that contacts the target gene promoter to induce transcription of IGF-I and MAPK related genes. Nongenomically, $\mathrm{E}_{2}$ can bind to membrane associated $\mathrm{ER} \alpha$ which then binds to the adaptor protein, Src collagen homologue (Shc) to form a protein complex consisting of ER $\alpha$ and Shc and/or ER $\alpha$ and IGF-IR. E 2 signals through the IGF-IR and activates MAPKp44/42, which can then phosphorylate ER $\alpha$ at the serine118 site to initiate transcription (txn) of MAPK related genes. CCNDs = Cyclin Ds; MAPKs = mitogen-activated protein kinases; DLK1 = delta-like 1 homolog; COL1A1 = collagen type I alpha 1.

shown that a pool of ERs resides in or is associated with the plasma membrane. These ERs utilize the membrane IGF-IR to rapidly signal through various kinase cascades that influence both transcriptional and nontranscriptional actions of estrogen [28]. In this study, UtLM cells treated with $\mathrm{E}_{2}$, showed upregulation of RAC1, a Rho GTPase involved in the regulation of several cellular processes that is often activated following stimulation of RTKs [24]. This gene expression of RAC1 was decreased upon IGF-IR silencing. These data indicate that $\mathrm{E}_{2}$ can directly, or through the involvement of the $\operatorname{ER} \alpha$, activate IGF-IR and MAPK signaling. The IGF-IR may serve as an anchor for the plasma membrane-associated $\mathrm{ER} \alpha$. Estradiol causes rapid phosphorylation of IGF-IR and Shc. It has been reported that activated Shc, after binding to $\operatorname{ER} \alpha$, serves as a transporter, which carries $\mathrm{ER} \alpha$ to Shcbinding sites on the activated IGF-I receptors [39], which subsequently signals to MAPKs and other pathways. Our immunoprecipitation results also show that these three proteins, ER $\alpha$, IGF-IR, and Shc, are associated with each other when UtLM cells are treated with $\mathrm{E}_{2}$. Therefore, we proposed that IGF-IR should be a key mediator in this interaction, and applied siIGF-IR methodology to knockdown the IGFIR gene to block the $\mathrm{E}_{2}$ effect on the interaction of these two pathways through their respective receptors. We found that siIGF-IR decreased the phosphorylation of IGF-IR $\beta$ and the activation of MAPKp44/42 induced by $\mathrm{E}_{2}$. At same time, $\mathrm{ER} \alpha$ phosphorylation at the serine 118 site was also attenuated. These findings indicate that IGF-IR $\beta$ activation is required in the rapid nongenomic response of $\mathrm{ER} \alpha$ following $\mathrm{E}_{2}$ exposure in UtLM cells. Silencing of IGF-IR abrogated the $\mathrm{ER} \alpha$ activity at the serine 118 site induced by $\mathrm{E}_{2}$ confirming a potential relationship between membrane-related signals and intracellular $\mathrm{ER} \alpha$, in agreement with the findings that $\mathrm{E}_{2}$ binds to cell membrane-associated $\mathrm{ER} \alpha$, which physically associates with the adaptor protein Shc through IGF-IR activation and induces its phosphorylation [39]. In turn, Shc binds GRB2 and Sos, which also results in the rapid activation of MAP kinase, and we have shown an association 
between IGF-IR and Grb2 and MAP kinase activation in fibroid tissue samples taken from women in the proliferative phase of the menstrual cycle $[9,40]$.

Therefore, the possible convergence of distinct ER $\alpha$ mediated genomic and/or nongenomic actions at multiple response elements provides an extremely fine control system in the regulation of target gene transcript [14] leading to the alternation of gene expression profiles found in this study. In conclusion, the results obtained in this study indicate that the two growth regulatory pathways, $\mathrm{E}_{2} / \mathrm{ER} \alpha$ and IGFI/IGF-IR, are tightly linked in UtLM cells. The $\mathrm{E}_{2}$ effects can occur through both genomic and nongenomic events, which involve IGF-IR activation of MAP kinase cascades mediated by the association between ER $\alpha$ ser118 and MAPKp44/42 (Figure 6). The observations that: (1) IGF-IR is required for the interaction and the differential expression of MAPK pathway-related genes mediated by $\mathrm{E}_{2}$; (2) IGF-I gene expression is responsive to $\mathrm{E}_{2}$; (3) the activation of alternative pathways induced by $\mathrm{E}_{2}$ when IGF-IR is silenced enhances our understanding of IGF-I/IGF-IR and $\mathrm{E}_{2} / \mathrm{ER} \alpha$ interactions and may suggest a multipronged or cocktail approach to fibroid treatment. Considering that the pure antiestrogen or anti-IGF-IR agents may only be partially effective in antagonizing $\mathrm{E}_{2}$-induced IGF-I/MAPK pathway activation and because other alternative pathways (EGFR) could compensate, it suggests that inhibitors of small downstream molecules, such as Src and ERKs, or transcription factors may better block these effects and could possibly serve as noninvasive adjuvant therapies for fibroids.

\section{Conflict of Interests}

No conflict of interests, financial or otherwise, is declared by the authors.

\section{Disclaimer}

This paper may be the work product of an employee or group of employees of the NIEHS, NTP, and NIH, however, the statements, opinions, or conclusions contained therein do not necessarily represent the statements, opinions, or conclusions of NIEHS, NTP, NIH, or the United States government.

\section{Acknowledgments}

The authors would like to thank Dr. Kyathanahalli Janardhan and Ms. Retha R. Newbold for their critical review of this paper. This research was supported, in part, by the National Toxicology Program (NTP) and the Intramural Research Program of the National Institutes of Health (NIH), National Institute of Environmental Health Sciences (NIEHS).

\section{References}

[1] T. Maruo, N. Ohara, J. Wang, and H. Matsuo, "Sex steroidal regulation of uterine leiomyoma growth and apoptosis," Human Reproduction Update, vol. 10, no. 3, pp. 207-220, 2004.

[2] C. L. Walker and E. A. Stewart, "Uterine fibroids: the elephant in the room," Science, vol. 308, no. 5728, pp. 1589-1592, 2005.
[3] X. Luo and N. Chegini, "The expression and potential regulatory function of MicroRNAs in the pathogenesis of leiomyoma," Seminars in Reproductive Medicine, vol. 26, no. 6, pp. 500-514, 2008.

[4] A. J. Jakimiuk, M. Bogusiewicz, R. Tarkowski et al., "Estrogen receptor $\alpha$ and $\beta$ expression in uterine leiomyomas from premenopausal women," Fertility and Sterility, vol. 82, no. 3, supplement, pp. 1244-1249, 2004.

[5] P. Bakas, A. Liapis, S. Vlahopoulos et al., "Estrogen receptor $\alpha$ and $\beta$ in uterine fibroids: a basis for altered estrogen responsiveness," Fertility and Sterility, vol. 90, no. 5, pp. 18781885, 2008.

[6] H. Asada, Y. Yamagata, T. Taketani et al., "Potential link between estrogen receptor- $\alpha$ gene hypomethylation and uterine fibroid formation," Molecular Human Reproduction, vol. 14, no. 9, pp. 539-545, 2008.

[7] J. Huang, J. Zou, B. Xu, Y. Zhang, X. Chen, and D. Liu, "Affect of insulin-like growth factor I and estradiol on the growth of uterine leiomyoma," Hunan Yi Ke da Xue Xue Bao, vol. 24, no. 1, pp. 29-32, 1999.

[8] G. P. Flake, J. Andersen, and D. Dixon, "Etiology and pathogenesis of uterine leiomyomas: a review," Environmental Health Perspectives, vol. 111, no. 8, pp. 1037-1054, 2003.

[9] L. Yu, K. Saile, C. D. Swartz et al., "Differential expression of receptor tyrosine kinases (RTKs) and IGF-I pathway activation in human uterine leiomyomas," Molecular Medicine, vol. 14, no. 5-6, pp. 264-275, 2008.

[10] K. Englund, B. Lindblom, K. Carlström, I. Gustavsson, P. Sjöblom, and A. Blanck, "Gene expression and tissue concentrations of IGF-I in human myometrium and fibroids under different hormonal conditions," Molecular Human Reproduction, vol. 6, no. 10, pp. 915-920, 2000.

[11] Y. Zhao, W. Zhang, and S. Wang, "The expression of estrogen receptor isoforms $\alpha, \beta$ and insulin-like growth factor-I in uterine leiomyoma," Gynecological Endocrinology, vol. 24, no. 10, pp. 549-554, 2008.

[12] C. D. Swartz, C. A. Afshari, L. Yu, K. E. Hall, and D. Dixon, "Estrogen-induced changes in IGF-I, Myb family and MAP kinase pathway genes in human uterine leiomyoma and normal uterine smooth muscle cell lines," Molecular Human Reproduction, vol. 11, no. 6, pp. 441-450, 2005.

[13] S. Li and J. A. McLachlan, "Estrogen-associated genes in uterine leiomyoma," Annals of the New York Academy of Sciences, vol. 948, pp. 112-120, 2001.

[14] M. Lanzino, C. Morelli, C. Garofalo et al., "Interaction between estrogen receptor alpha and insulin/IGF signaling in breast cancer," Current Cancer Drug Targets, vol. 8, no. 7, pp. 597-610, 2008.

[15] M. A. Shupnik, "Crosstalk between steroid receptors and the c-Src-receptor tyrosine kinase pathways: implications for cell proliferation," Oncogene, vol. 23, no. 48, pp. 7979-7989, 2004.

[16] R. Suter and J. A. Marcum, "The molecular genetics of breast cancer and targeted therapy," Biologics, vol. 1, no. 3, pp. 241258, 2007.

[17] R. X. D. Song, Z. Zhang, and R. J. Santen, "Estrogen rapid action via protein complex formation involving ER $\alpha$ and Src," Trends in Endocrinology and Metabolism, vol. 16, no. 8, pp. 347-353, 2005.

[18] Z. Zhang, R. Kumar, R. J. Santen, and R. X. D. Song, "The role of adapter protein Shc in estrogen non-genomic action," Steroids, vol. 69, no. 8-9, pp. 523-529, 2004.

[19] X. Di, L. Yu, A. B. Moore et al., "A low concentration of genistein induces estrogen receptor-alpha and insulin-like growth factor-I receptor interactions and proliferation in 
uterine leiomyoma cells," Human Reproduction, vol. 23, no. 8, pp. 1873-1883, 2008.

[20] K. B. Reddy and S. Glaros, "Inhibition of the MAP kinase activity suppresses estrogen-induced breast tumor growth both in vitro and in vivo," International Journal of Oncology, vol. 30, no. 4, pp. 971-975, 2007.

[21] E. N. Nierth-Simpson, M. M. Martin, T. C. Chiang et al., "Human uterine smooth muscle and leiomyoma cells differ in their rapid 17/J-estradiol signaling: implications for proliferation," Endocrinology, vol. 150, no. 5, pp. 2436-2445, 2009.

[22] T. L. Hermon, A. B. Moore, L. Yu, G. E. Kissling, F. J. Castora, and D. Dixon, "Estrogen receptor alpha $(\mathrm{ER} \alpha)$ phosphoserine-118 is highly expressed in human uterine leiomyomas compared to matched myometrium," Virchows Archiv, vol. 453, no. 6, pp. 557-569, 2008.

[23] W. J. Conover and R. L. Iman, "Analysis of covariance using the rank transformation," Biometrics, vol. 38, no. 3, pp. 715724, 1982.

[24] M. R. Schiller, "Coupling receptor tyrosine kinases to Rho GTPases-GEFs what's the link," Cellular Signalling, vol. 18, no. 11, pp. 1834-1843, 2006.

[25] W. Li, J. Fawcett, H. R. Widmer, P. J. Fielder, R. Rabkin, and G. A. Keller, "Nuclear transport of insulin-like growth factor-I and insulin-like growth factor binding protein-3 in opossum kidney cells," Endocrinology, vol. 138, no. 4, pp. 1763-1766, 1997.

[26] H. Yamashita, M. Nishio, T. Toyama et al., "Low phosphorylation of estrogen receptor $\alpha(\mathrm{ER} \alpha)$ serine 118 and high phosphorylation of ER $\alpha$ serine 167 improve survival in ER-positive breast cancer," Endocrine-Related Cancer, vol. 15, no. 3, pp. 755-763, 2008.

[27] L. Björnström and M. Sjöberg, "Mechanisms of estrogen receptor signaling: convergence of genomic and nongenomic actions on target genes," Molecular Endocrinology, vol. 19, no. 4, pp. 833-842, 2005.

[28] E. R. Levin, "Integration of the extranuclear and nuclear actions of estrogen," Molecular Endocrinology, vol. 19, no. 8, pp. 1951-1959, 2005.

[29] Z. Madak-Erdogan, K. J. Kieser, H. K. Sung, B. Komm, J. A. Katzenellenbogen, and B. S. Katzenellenbogen, "Nuclear and extranuclear pathway inputs in the regulation of global gene expression by estrogen receptors," Molecular Endocrinology, vol. 22, no. 9, pp. 2116-2127, 2008.

[30] M. Marino, P. Galluzzo, and P. Ascenzi, "Estrogen signaling multiple pathways to impact gene transcription," Current Genomics, vol. 7, no. 8, pp. 497-508, 2006.

[31] T. P. Garrington and G. L. Johnson, "Organization and regulation of mitogen-activated protein kinase signaling pathways," Current Opinion in Cell Biology, vol. 11, no. 2, pp. 211-218, 1999.

[32] C. Widmann, S. Gibson, M. B. Jarpe, and G. L. Johnson, "Mitogen-activated protein kinase: conservation of a threekinase module from yeast to human," Physiological Reviews, vol. 79, no. 1, pp. 143-180, 1999.

[33] A. Brunet, D. Roux, P. Lenormand, S. Dowd, S. Keyse, and J. Pouysségur, "Nuclear translocation of p42/p44 mitogenactivated protein kinase is required for growth factor-induced gene expression and cell cycle entry," EMBO Journal, vol. 18, no. 3, pp. 664-674, 1999.

[34] A. V. Khokhlatchev, B. Canagarajah, J. Wilsbacher et al., "Phosphorylation of the MAP kinase ERK2 promotes its homodimerization and nuclear translocation," Cell, vol. 93, no. 4, pp. 605-615, 1998.
[35] P. G. Ganchevska, A. P. Uchikov, V. S. Ishev, I. A. Batashki, V. N. Nizamov, and E. H. Uchikova, "Estrogen receptors-known and unknown biological functions," Folia medica, vol. 48, no. 2, pp. 5-10, 2006.

[36] J. C. M. Tsibris, J. Segars, D. Coppola et al., "Insights from gene arrays on the development and growth regulation of uterine leiomyomata," Fertility and Sterility, vol. 78, no. 1, pp. 114$121,2002$.

[37] P. C. Leppert, W. H. Catherino, and J. H. Segars, "A new hypothesis about the origin of uterine fibroids based on gene expression profiling with microarrays," American Journal of Obstetrics and Gynecology, vol. 195, no. 2, pp. 415-420, 2006.

[38] M. M. Grudzien, P. S. Low, P. C. Manning, M. Arredondo, R. J. Belton, and R. A. Nowak, "The antifibrotic drug halofuginone inhibits proliferation and collagen production by human leiomyoma and myometrial smooth muscle cells," Fertility and Sterility, vol. 93, no. 4, pp. 1290-1298, 2010.

[39] R. J. Santen, R. X. Song, Z. Zhang et al., "Long-term estradiol deprivation in breast cancer cells up-regulates growth factor signaling and enhances estrogen sensitivity," EndocrineRelated Cancer, vol. 12, no. 1, supplement, pp. S61-S73, 2005.

[40] Y. Mebratu and Y. Tesfaigzi, "How ERK1/2 activation controls cell proliferation and cell death is subcellular localization the answer?” Cell Cycle, vol. 8, no. 8, pp. 1168-1175, 2009. 

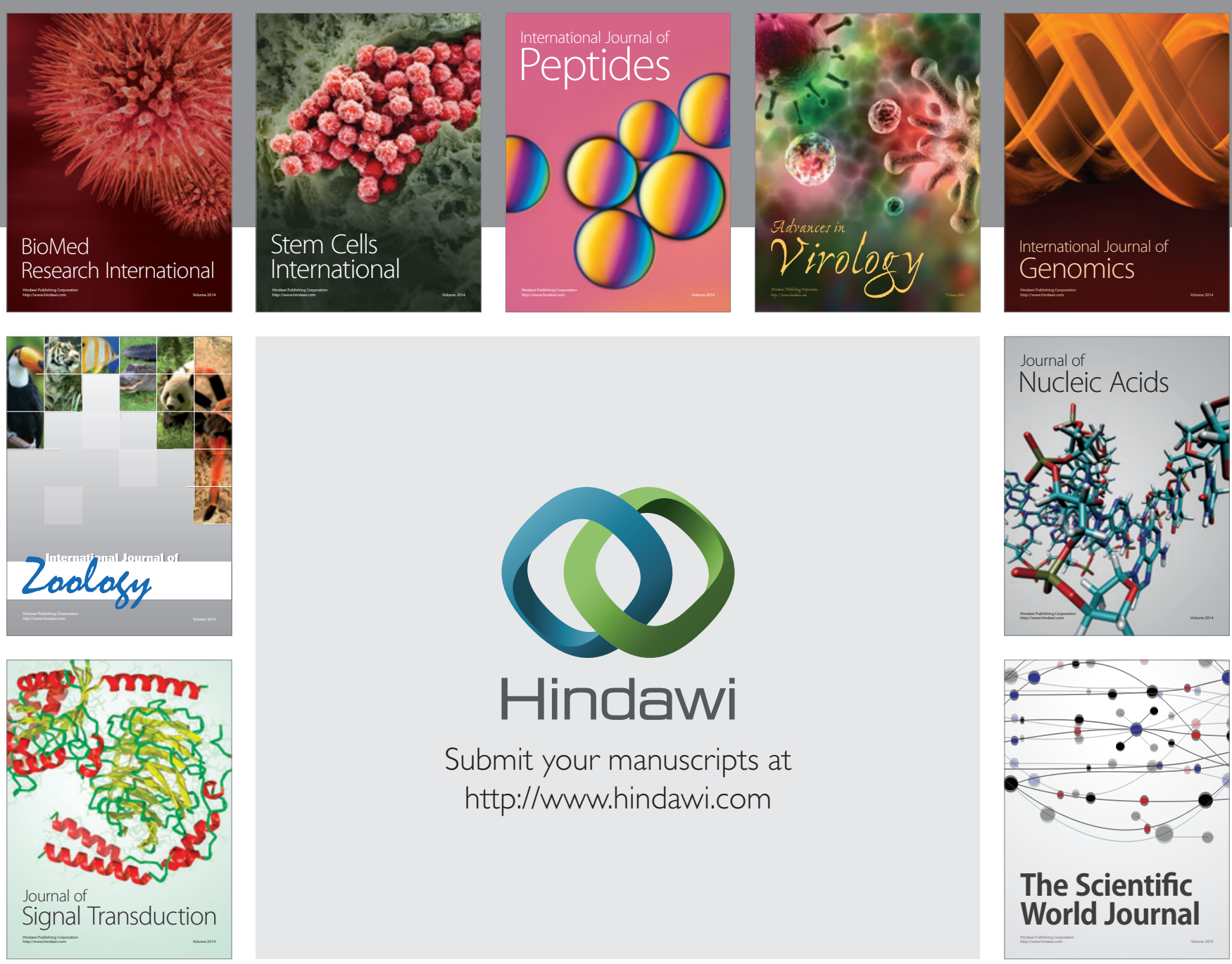

Submit your manuscripts at

http://www.hindawi.com
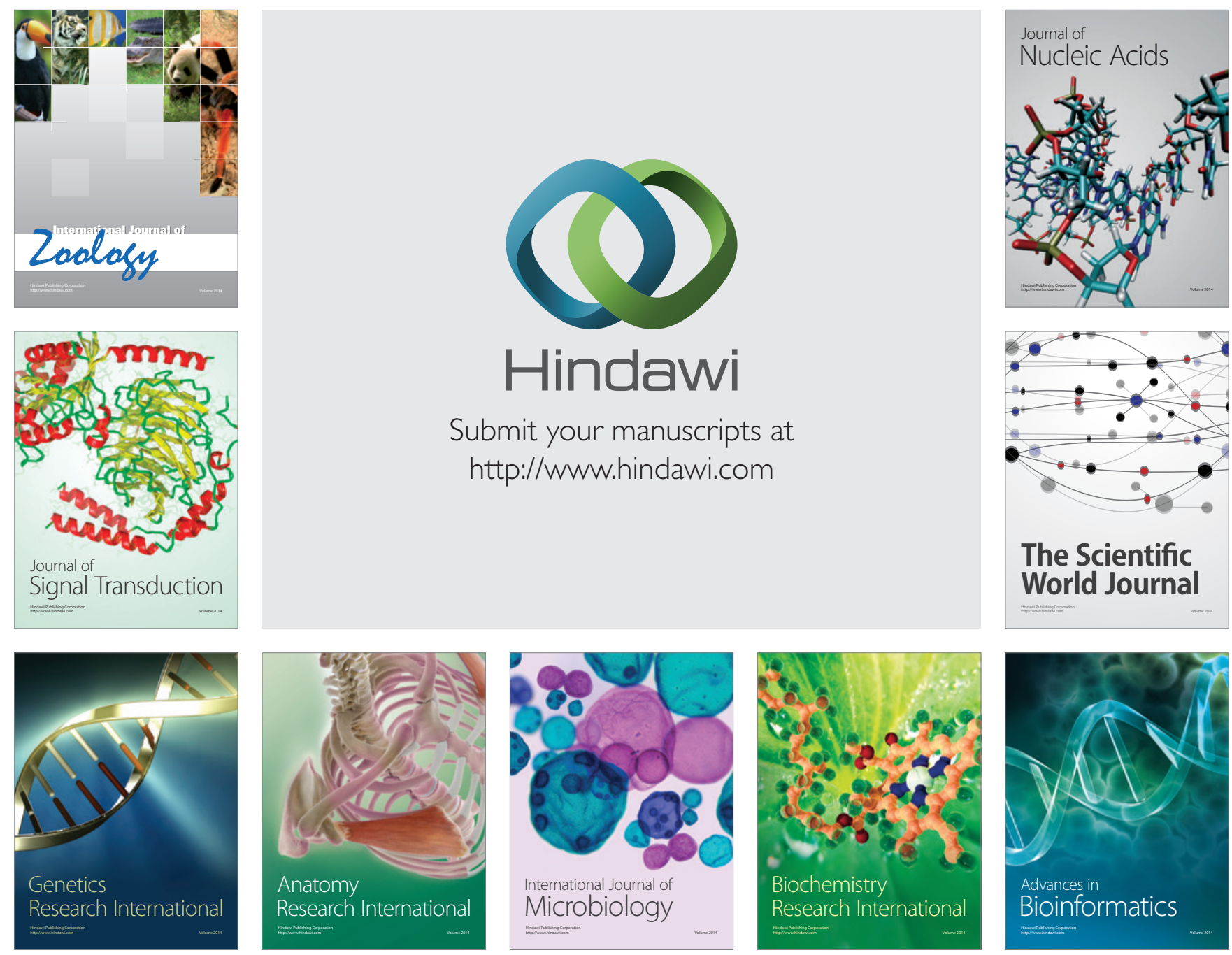

The Scientific World Journal
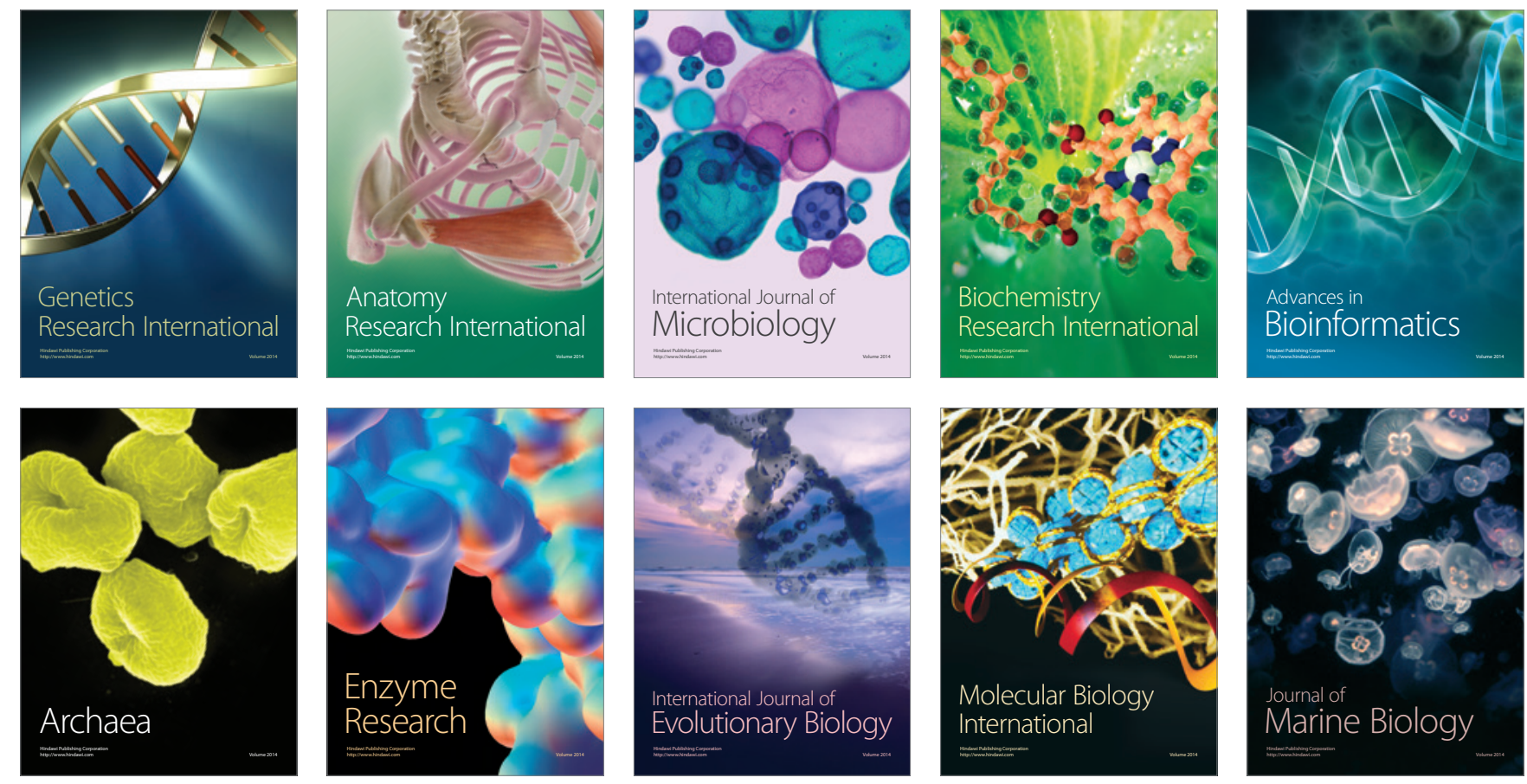